\title{
Quantification of Regional Myocardial Blood Flow Using First-Pass Multidetector-Row Computed Tomography and Adenosine Triphosphate in Coronary Artery Disease
}

\author{
Teruhito Kido; Akira Kurata*; Hiroshi Higashino; Yuma Inoue; \\ Rene Epunza Kanza; Hideki Okayama*; Jitsuo Higaki*; \\ Kenya Murase**; Teruhito Mochizuki
}

\begin{abstract}
Background The feasibility of using cardiac multidetector-row computed tomography (MDCT) technology in the quantitative assessment of myocardial blood flow (MBF) using the adenosine triphosphate (ATP) load technique was investigated in the present study.

Methods and Results The study group comprised 14 patients (11 men, 3 women, age range 52-79 years, mean age 69.2 years) who underwent cardiac cine MDCT using the ATP-load technique. MBF was estimated from the slope of the linear regression equation with Patlak plots analysis. The overall average MBF was $1.83 \pm 0.62 \mathrm{ml}$. $\mathrm{g}^{-1} \cdot \mathrm{min}^{-1}$. Mean MBF in territories with stenosis on coronary angiography was $1.19 \pm 0.36 \mathrm{ml} \cdot \mathrm{g}^{-1} \cdot \mathrm{min}^{-1}$ and $2.06 \pm 0.54 \mathrm{ml} \cdot \mathrm{g}^{-1} \cdot \mathrm{min}^{-1}(\mathrm{p}<0.01)$ in territories without stenosis. The average MBF in territories with moderate to severe ischemia on myocardial perfusion scintigraphy was $1.32 \pm 0.14 \mathrm{ml} \cdot \mathrm{g}^{-1} \cdot \mathrm{min}^{-1}$ and $1.95 \pm 0.64 \mathrm{ml} \cdot \mathrm{g}^{-1} \cdot \mathrm{min}^{-1}$ $(\mathrm{p}<0.01)$ in territories without ischemia.
\end{abstract}

Conclusion MDCT can be used to quantify MBF using first-pass dynamic data. (Circ J 2008; 72: 1086-1091)

Key Words: Computed tomography (CT); Ischemia; Perfusion

$\mathbf{E}$ lectrocardiography (ECG)-gated multidetector-row computed tomography (MDCT) has developed remarkably in the past several years, with improvements in spatial and temporal resolution ${ }^{1-3}$ Several studies have focused on its usefulness for assessing the coronary artery lumen, and others studies have demonstrated its capability to evaluate coronary plaques, so the technique has gained acceptance as a valuable tool for coronary imaging in the clinical setting.-11 Because of the retrospective acquisition, the same data acquired for coronary computed tomography (CT) imaging can also be reconstructed over a cardiac cycle, allowing dynamic cardiac imaging; and we recently reported that wall motion and systolic thickening could be accurately estimated as functional parameters.2-14 ECG-gated MDCT technology can therefore evaluate cardiac blood flow from virtually any perspective, including important angles for the interventional approach and for myocardial perfusion.

Of these potential applications of cardiac MDCT, myocardial perfusion has so far been less investigated, but its assessment is important for the diagnosis of ischemia and

(Received November 21, 2007; revised manuscript received February 5, 2008; accepted February 7, 2008)

Department of Diagnostic and Therapeutic Radiology, *Department of Integrated Medicine and Informatics, Ehime University Graduate School of Medicine, Toon and **Medical Physics and Engineering, Osaka University Graduate School of Medicine, Suita, Japan

Nothing to disclose about grants.

Mailing address: Teruhito Kido, MD, Department of Diagnostic and Therapeutic Radiology, Ehime University Graduate School of Medicine, Shitsukawa, Toon 791-0295, Japan. E-mail: kids@ehm.enjoy. ne.jp

All rights are reserved to the Japanese Circulation Society. For permissions, please e-mail: cj@j-circ.or.jp infarction, and for the therapeutic strategy and follow-up. An evaluation of myocardial blood flow (MBF) is also important for studying the pathophysiology of the disease process. A few studies have reported the utility of cardiac MDCT to qualitatively assess myocardial perfusion using a late-enhancement protocol and the adenosine triphosphate (ATP) load technique, ${ }^{15-19}$ but quantitative evaluation studies have not been carried out.

Therefore, in this study, we investigated the feasibility of cardiac MDCT technology for quantitative assessment of MBF using the ATP-load technique.

\section{Methods}

\section{Patients}

From April 2006 to May 2007, taking the exclusion criteria into account, 14 patients (11 men, 3 women, age range 52-79 years, mean 69.2 years) underwent ATP-provocation contrast enhanced MDCT, stress thallium-201 myocardial perfusion scintigraphy (MPS), and conventional coronary angiography (CAG). The entry criteria were: (i) de novo effort or rest angina (documented ST-T change on ECG, or relieved by administration of nitroglycerin); (ii) no history of CAG; and (iii) asymptomatic patients with a high probability of coronary artery disease (CAD) (ie, multiple coronary risk factors) or abnormal findings on stress ECG and single-photon emission computed tomography (SPECT). The ATP-load cardiac CT and CAG had an average 40-day interval, and the ATP-load cardiac CT and MPS inspection had an average interval of 29.2 days. Patient characteristics are shown in Table 1. No patient had a history of previous myocardial infarction (MI) and there were no significant differences between men and women in age, clinical symptoms and coronary risk factors. 
The exclusion criteria included: (i) MI; (ii) unstable angina (onset of angina within past month; severe or worsening clinical symptoms); (iii) greater than first degree atrioventricular block; (iv) deteriorated renal function (serum creatinine $>1.5 \mathrm{mg} / \mathrm{dl}$ ); (v) pregnancy, hyperthyroidism or a known allergic reaction to contrast media; (vi) severe left ventricular (LV) dysfunction (LV ejection fraction $<20 \%$ ); (vii) known history of bronchial asthma, and (viii) congestive heart failure of New York Heart Association class IV.

All patients gave informed consent and the protocol was approved by the hospital's ethics committee.

\section{ATP-Load Cardiac CT Protocol}

Fig 1 shows the ATP-load cardiac CT protocol. Patients were scanned in a fasting state while supine. They had refrained from having caffeine (coffee) from the evening before the test.

ATP (ADETPHOS-L, Kowa, Tokyo, Japan) was infused over $3 \mathrm{~min}$ at a rate of $0.16 \mathrm{mg} \cdot \mathrm{kg}^{-1} \cdot \mathrm{min}^{-1}$ using an infusion pump system (Teru-Fusion, Syringepump. TE-3320C, Terumo, Tokyo, Japan) through a peripheral venous catheter on the opposite side of the cubital vein to the contrast infusion. Three minutes after the ATP infusion, $20 \mathrm{ml}$ of contrast medium and $20 \mathrm{ml}$ of saline was injected at a rate of $3 \mathrm{ml} / \mathrm{s}$. Contrast medium passage in the left atrium (LA) was monitored and after it had reached the LA, scanning at the level of the middle of the LV was performed in cine mode during breath-holding for 20s. 16-MDCT (LightSpeed Ultra 16, GE Healthcare, Milwaukee, WI, USA) was used with the following parameters: non-ECG-gated cine scan, 912 channel detectors along the gantry and 16 channel detectors along the $\mathrm{z}$-axis, tube voltage $120 \mathrm{kV}$, tube current $50 \mathrm{~mA}$, scan FOV $25 \mathrm{~cm}$, gantry rotation 0.6 s/rotation, matrix $512 \times$ 512 , slice width $200 \mathrm{~mm}$. The region of interest (ROI) was placed on the obtained dynamic data and the time-density curve was analyzed by Patlak plot methods (Fig 2).

\section{$M B F$}

MBF was estimated from the slope of the linear regres-
Table 1 Patients' Characteristics

\begin{tabular}{lc}
\hline \hline General & \\
Age (years) & $69.2 \pm 8.3$ \\
Male (\%) & 78.6 \\
Risk factors & \\
Hypertenstion & $10(71 \%)$ \\
Diabetes mellitus & $7(50 \%)$ \\
Hyperlipidemia & $10(71 \%)$ \\
Smoking & $7(50 \%)$ \\
Family history & $2(14 \%)$ \\
Symptoms & \\
Effort chest pain & $8(57 \%)$ \\
Rest chest pain & $2(14 \%)$ \\
None & $4(29 \%)$ \\
Interval time (days) & \\
CT to CAG & $40 \pm 37.4$ \\
CT to SPECT & $29.2 \pm 7.1$ \\
\hline
\end{tabular}

$C T$, computed tomography; CAG, coronary angiography; SPECT, singlephoton emission computed tomography.

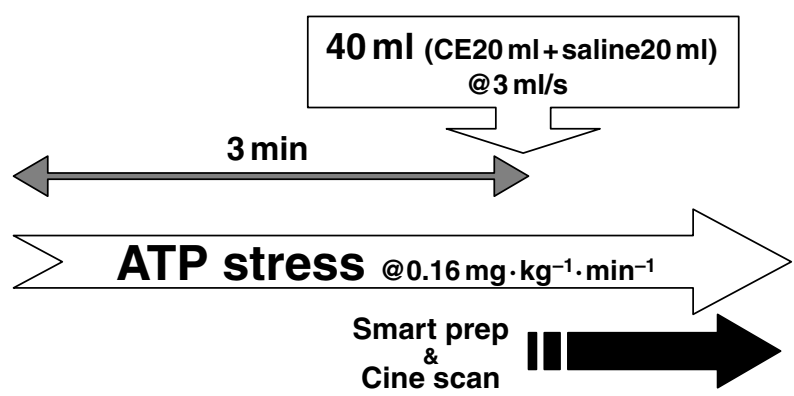

Fig 1. Adenosine triphosphate (ATP) load cardiac computed tomography protocol is illustrated.

sion equation between Int_Cb(t)/Cb(t) and $\mathrm{C}(\mathrm{t}) / \mathrm{Cb}(\mathrm{t})$, where $\mathrm{C}(\mathrm{t})$ and $\mathrm{Cb}(\mathrm{t})$ represent the concentration of contrast agent at time $\mathrm{t}$ in the tissue and blood, respectively, and Int_ $\mathrm{Cb}(\mathrm{t})$ is the integral of $\mathrm{Cb}(\mathrm{t}){ }^{20}$ Fig 2 shows the ROI on the MDCT image, time-density curve and Patlak plot
A
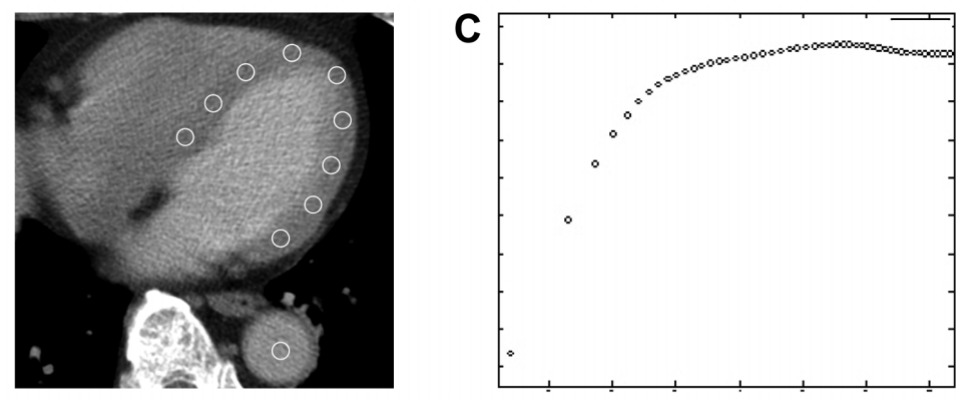

B

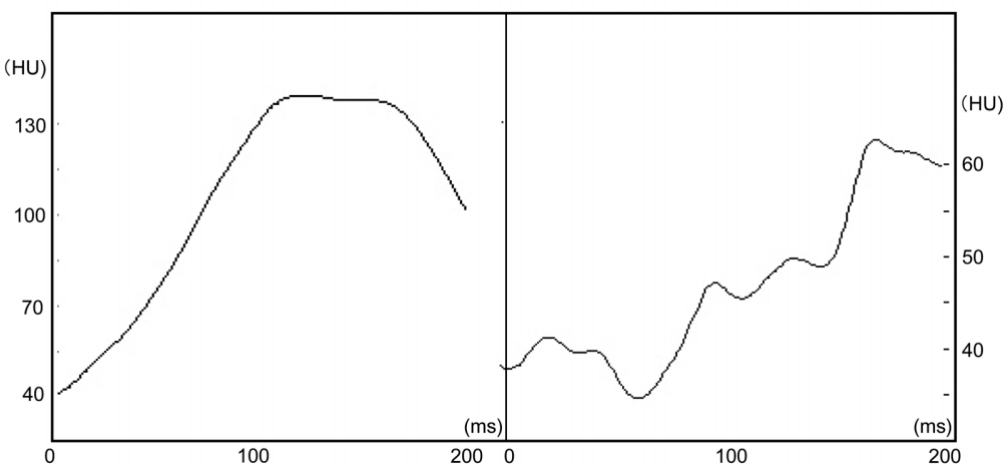

Fig 2. (A) As shown in the figure, ROI was set up in the myocardium and descending aorta. (B) Time density curves of the myocardium and aorta were obtained. (C) We applied the Patlak plot analysis by making time density curve of aorta as an input function. And myocardial blood flow was calculated from slope of the graph. 


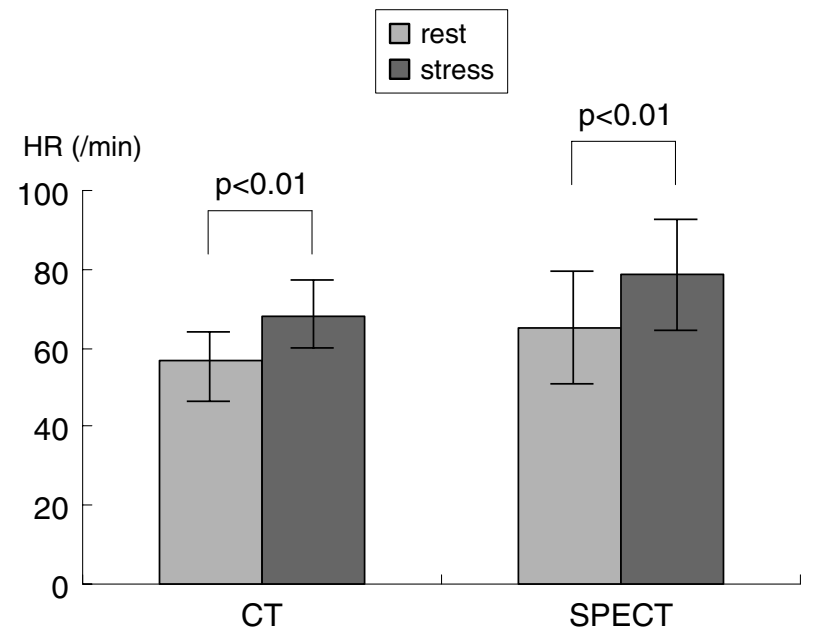

Fig 3. Heart rate (HR) changes between pre- and post- adenosine triphosphate load tests in computed tomography (CT) and single-photon emission computed tomography (SPECT).

graphical image.

\section{Stress Thallium-201 MPS}

Stress thallium-201 MPS was performed according to the American College of Cardiology (ACC)/American Heart Association (AHA)/American Society of Nuclear Cardiology (ASNC) guidelines for the clinical use of cardiac radionuclide imaging. ${ }^{21}$ Stress was induced pharmacologically through intravenous infusion of ATP ( 5 min infusion of $0.16 \mathrm{mg} \cdot \mathrm{kg}^{-1} \cdot \mathrm{min}^{-1}$ ) as described by Miyagawa et $\mathrm{al}^{22}$ Standard ECG, vital signs and general condition were continuously monitored. Three minutes after the continuous infusion of ATP, $111 \mathrm{MBq}$ of thallium-201 (Daiich Radioisotope Laboratories, Tokyo, Japan) was injected intravenously and flushed with saline. Early-phase SPECT was acquired $10 \mathrm{~min}$ after the start of ATP stress infusion and late SPECT images were acquired $4 \mathrm{~h}$ later.

SPECT images were acquired using a 3-headed SPECT system (GCA 9300; Toshiba, Tokyo, Japan and Scintipac 2400; Shimadzu, Kyoto, Japan). Tomographic reconstruction was performed using a standard filtered back-projection technique with a Lamp filter to produce a transaxial tomogram. Neither scatter nor attenuation correction was applied. From the transaxial tomograms, the long-axis of the LV was identified and oblique-angled tomograms were generated (ie, vertical long-axis, short-axis and horizontal long-axis tomograms).

The LV was classified into 17 segments according to the AHA classification, and classified into each coronaryartery rule region. The percent uptake of each segment was calculated: $\geq 80 \%=0, \geq 66 \%=1$ point, $\geq 50 \%=2$ points, $\geq 35 \%=3$ points, $<35 \%=4$ points; scoring was carried out, and the summed stress score (SSS) of the whole cardiac muscle and the percent total myocardium ischemia for each coronary artery were calculated.23-26 The SSS was $1-2=$ normal, $3-6=$ mildly abnormal, $7-9=$ moderately abnormal, 10 or more $=$ severely abnormal, and the percent total myocardium ischemia was scored as $<5 \%=$ normal, $>5 \%$ and $<10 \%=$ mildly abnormal, $>10 \%$ and $<16 \%=$ moderately abnormal, and $>16 \%=$ severely abnormal.

This study designated moderately abnormal and severely abnormal as significant ischemia.

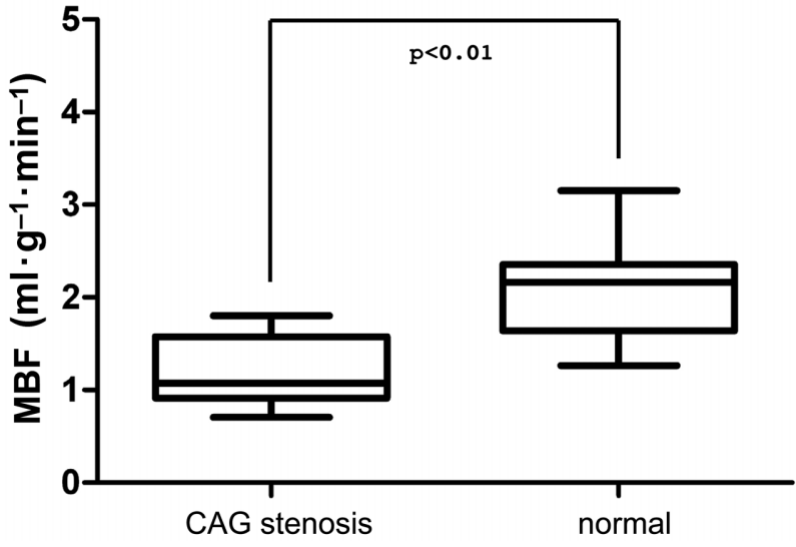

Fig 4. Mean myocardial blood flow (MBF) in territories with stenosis on coronary angiography $(\mathrm{CAG}, \mathrm{n}=11)$ was $1.19 \pm 0.36 \mathrm{ml} \cdot \mathrm{g}^{-1} \cdot \mathrm{min}^{-1}$ $($ mean $\pm S D)$, while mean MBF in territories without stenosis $(n=31)$ was $2.06 \pm 0.54 \mathrm{ml} \cdot \mathrm{g}^{-1} \cdot \mathrm{min}^{-1}$.

$C A G$

Conventional CAG images were obtained routinely using 5-Fr catheters with an angiography system (Philips Allura Xper FD10/10). Acquisition parameters were: $15 \mathrm{frame} / \mathrm{s}$ and manual injection of contrast medium $(2.5 \mathrm{ml} / \mathrm{s})$. The angiograms were saved to CD-ROM and interpreted by 2 experienced cardiologists who were unaware of the MDCT results. The results of CAG were quantitatively evaluated using commercially available software (QCA-CMS system version 3.0, MEDIS, Leiden, The Netherlands). In both assessments, coronary segments were defined according to the AHA classification (15-segment model) and stenosis $\geq 75 \%$ was defined as significant.

\section{Statistical Analysis}

Data are presented as the mean value $\pm \mathrm{SD}$ as appropriate. Agreement between perfusion CT and MPS was statistically analyzed with Fisher's exact probability test. For determining the accuracy of coronary CT-angiography, the following calculations were used: assessability $\%=100 \times$ number of segments that could be evaluated/all segments; sensitivity $\%=100 \times$ number of stenoses detected/all stenoses evaluated by CT-angiography; specificity $\%=100 \times$ number of non-stenoses assessed/all non-stenoses evaluated by CTangiography. All statistical analyses were performed using SPSS software (version 11.1; SPSS, Chicago, IL, USA); $\mathrm{p}<0.05$ was considered significant.

\section{Results}

All 14 patients completed the ATP stress MDCT protocol without significant side-effects: 7 patients complained of feeling flushed, and 3 complained of chest discomfort; however, all of these events were transient and disappeared soon after the termination of ATP infusion, and none required aminophylline infusion to reverse the adverse effects. The mean heart rate in the ATP post-stress state was significantly higher than that in the ATP pre-stress state (Fig 3).

$C A G$

In CAG, significant stenosis ( $\geq 75 \%)$ was detected in 11 of 42 main coronary branches in 9 of 14 patients: 7 patients 


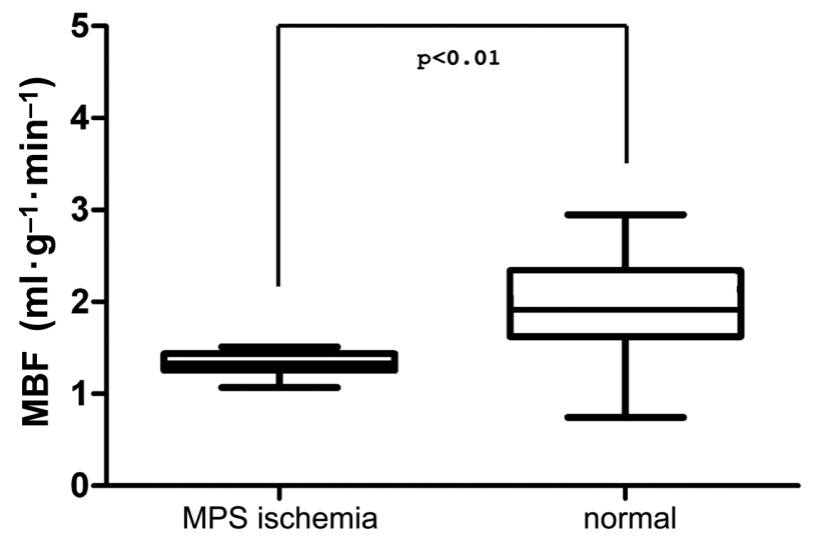

Fig 5. Average myocardial blood flow (MBF) in territories with moderate to severe ischemia on myocardial perfusion scintingraphy (MPS, $\mathrm{n}=8$ ) was $1.32 \pm 0.14 \mathrm{ml} \cdot \mathrm{g}^{-1} \cdot \mathrm{min}^{-1}($ mean $\pm \mathrm{SD})$, while mean MBF in territories without severe ischemia $(n=34)$ was $1.95 \pm 0.64 \mathrm{ml}$. $\mathrm{g}^{-1} \cdot \mathrm{min}^{-1}$.

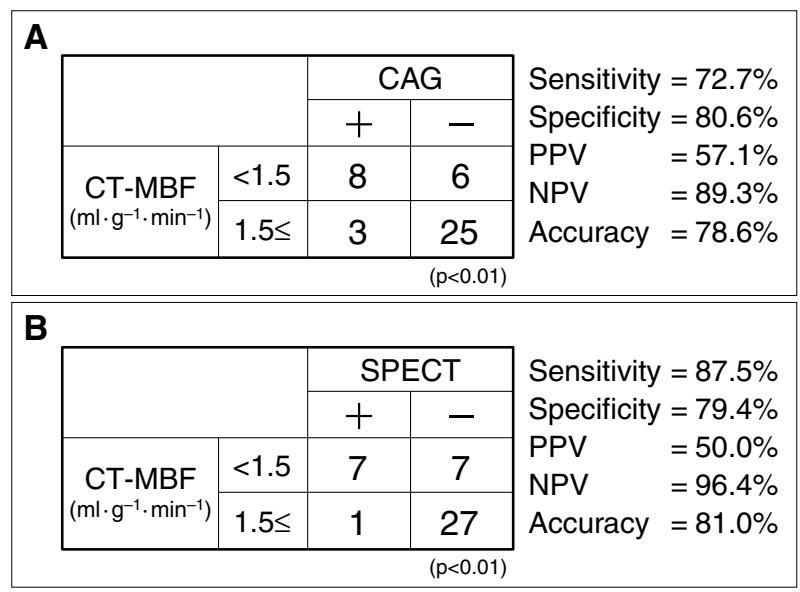

Fig 6. When the cutoff value of computed tomography-myocardial blood flow (CT-MBF) was set at $1.5 \mathrm{ml} \cdot \mathrm{g}^{-1} \cdot \mathrm{min}^{-1}$, there were good correlation between CT-MBF and single-photon emission computed tomography (SPECT), and between CT-MBF and coronary angiography (CAG).
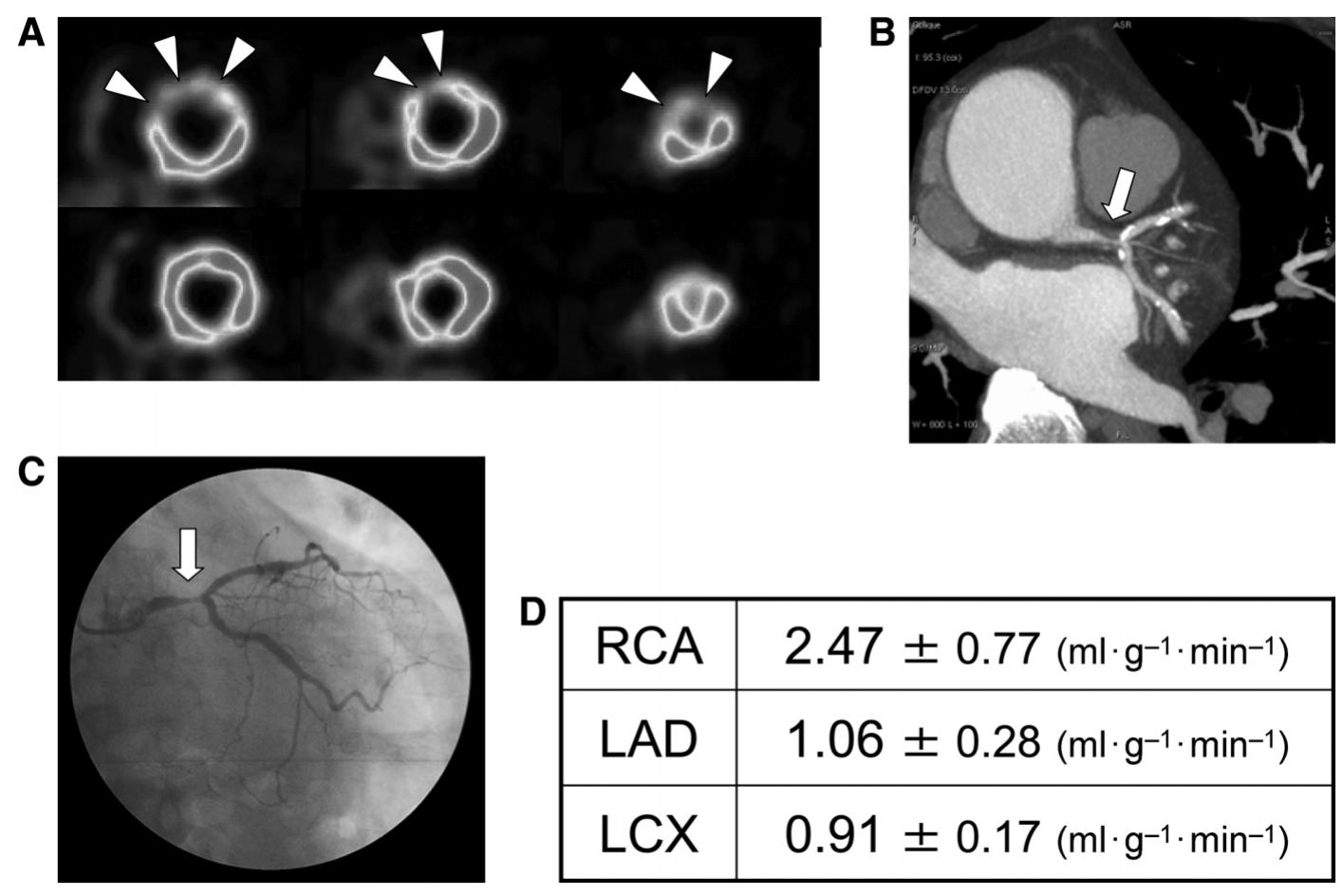

\begin{tabular}{|l|l|}
\hline RCA & $2.47 \pm 0.77\left(\mathrm{ml} \cdot \mathrm{g}^{-1} \cdot \mathrm{min}^{-1}\right)$ \\
\hline LAD & $1.06 \pm 0.28\left(\mathrm{ml} \cdot \mathrm{g}^{-1} \cdot \mathrm{min}^{-1}\right)$ \\
\hline LCX & $0.91 \pm 0.17\left(\mathrm{ml} \cdot \mathrm{g}^{-1} \cdot \mathrm{min}^{-1}\right)$ \\
\hline
\end{tabular}

Fig 7. A case of effort angina pectoris. (A) Myocardial perfusion scintingraphy revealed a redistribution in the anterior and lateral walls. (B) Computed tomography-angiography detected a stenotic segment with plaque in left main trunk (LMT). (C) Coronary angiography shows 99\% atenosis in LMT. (D) Mean myocardial blood flow (MBF) in the territories of left anterior descending and left circumflex arteries (LAD and LCX) were lower than the MBF in the territory of right coronary artery (RCA).

had 1-vessel disease, 2 had 2-vessel disease, and none had 3 -vessel disease. Of the 11 stenoses, 8 were in the left anterior descending (LAD) artery, 2 were in the left circumflex artery (LCX), and 1 was in the right coronary artery (RCA).

\section{SPECT}

Moderate to severe abnormal findings were seen in 6 of 14 patients ( 8 ischemic segments, 34 non-ischemic segments) on ${ }^{201}$ Tl SPECT: 4 patients had 1-vessel disease, 2 had 2-vessel disease, and none had 3-vessel disease. Of the
8 ATP-loaded MPS-positive territories, 4 were in the LAD territory, 4 were in the RCA territory, and none were in the LCX territory.

\section{MBF on MDCT}

The overall average $\mathrm{MBF}$ in the 42 main coronary territories of 14 patients was $1.83 \pm 0.62 \mathrm{ml} \cdot \mathrm{g}^{-1} \cdot \mathrm{min}^{-1}$. Average MBF was $1.51 \pm 0.65 \mathrm{ml} \cdot \mathrm{g}^{-1} \cdot \mathrm{min}^{-1}$ in the LAD, $2.11 \pm$ $0.69 \mathrm{ml} \cdot \mathrm{g}^{-1} \cdot \mathrm{min}^{-1}$ in the LCX, and $1.89 \pm 0.38 \mathrm{ml} \cdot \mathrm{g}^{-1} \cdot \mathrm{min}^{-1}$ in the RCA. On CAG the mean MBF in territories with 
stenosis $(\mathrm{n}=11)$ was $\mathrm{ml} \cdot \mathrm{g}^{-1} \cdot \mathrm{min}^{-1}$ and $2.06 \pm 0.54 \mathrm{ml} \cdot \mathrm{g}^{-1}$. $\mathrm{min}^{-1}$ in territories without stenosis $(\mathrm{n}=31)(\mathrm{p}<0.01)($ Fig 4$)$. On MPS the average MBF in territories with moderate to severe ischemia $(\mathrm{n}=8)$ was $1.32 \pm 0.14 \mathrm{ml} \cdot \mathrm{g}^{-1} \cdot \mathrm{min}^{-1}$ and $1.95 \pm 0.64 \mathrm{ml} \cdot \mathrm{g}^{-1} \cdot \mathrm{min}^{-1}$ in territories without ischemia $(\mathrm{n}=34)(\mathrm{p}<0.01)($ Fig 5). As compared with normal territories, significant differences in the average $\mathrm{MBF}$ were in territories with ischemia on MPS, or with stenosis on CAG $(\mathrm{p}<0.01)$.

When the cutoff value of CT-MBF was set at $1.5 \mathrm{ml} \cdot \mathrm{g}^{-1}$. $\mathrm{min}^{-1}$, there was good correlation between CT-MBF and SPECT, and between CT-MBF and CAG. CT-MBF vs CAG: sensitivity $=72.7 \%$, specificity $=80.6 \%, \mathrm{PPV}=57.1 \%$, $\mathrm{NPV}=89.3 \%$, accuracy $=78.6 \%$; CT-MBF vs SPECT: sensitivity $=87.5 \%$, specificity $=79.4 \%, \mathrm{PPV}=50.0 \%, \mathrm{NPV}=$ $96.4 \%$, accuracy $=81.0 \%$ (Fig 6).

\section{Discussion}

To our knowledge, this is the first report of using MDCT to quantify MBF using the ATP stress test in patients with CAD.

A myocardial perfusion abnormality is an important step in the ischemic cascade, and it is useful to assess the extent and severity of myocardial ischemia for risk stratification of patients with CAD. Clinically, MBF is quantified using MPS,2 magnetic resonance imaging (MRI) ${ }^{27,28}$ or positron emission tomography (PET)29,30 In previous studies using PET or MRI, a correlation between the degree of coronary stenosis and MBF has been found 31 Although quantification analysis of MBF is generally done with dynamic MRI, PET etc, special equipment is required, which is expensive, and it has limited spatial resolution. For MRI, patients with a pacemaker are contraindicated, and in PET, the pretreatment is complicated and time-consuming. If MDCT is able to effectively assess MBF, myocardial perfusion information can be obtained much more simply during a short period of time.

Recently, several reports of myocardial perfusion imaging using MDCT have stated that ECG-gated MDCT was able to depict ischemia in patients with CAD, and the findings agreed with those for MPS and CAG, comparing pre- and post-provocation tests with ATP; however, they were qualitative or visual assessments. In the present study, the measurement of MBF was successful as a quantitative analysis (Fig 7) and our results were validated by the SSS in MPS and the severity of stenosis on CAG. Although the assessment of coronary stenosis is often difficult in cases of severe calcification in the coronary arterial wall, MBF measurement is still possible and the information obtained of great benefit for estimating coronary stenosis. In this study, the HR increased during ATP loading, and there were data that could not be analyzed because of motion artifacts; however, the data could be interpolated from the dynamic scan.

We used only $20 \mathrm{ml}$ of $300 \mathrm{mg}-\mathrm{I} / \mathrm{ml}$ contrast medium, which considerably reduced the likelihood of side-effects in the kidney. However, the contrast resolution of MDCT was much less than that of MRI, so determining the optimal amount of contrast medium for evaluation requires further examination.

Our results show that MBF on ATP load decreases in the ischemic territories shown by CAG and MPS, which was encouraging because they suggested the possibility of quantitative analysis of $\mathrm{MBF}$ using first-pass dynamic MDCT; however, these values were somewhat lower than the values reported for PET-NH3, -oxygen15 and dynamic MRI. In past examinations using PET, MBF of the normal myocardium using an ATP load was $3-5 \mathrm{ml} \cdot \mathrm{g}^{-1} \cdot \mathrm{min}^{-1}$, and at rest it was $1.0-1.5 \mathrm{ml} \cdot \mathrm{g}^{-1} \cdot \mathrm{min}^{-1},{ }^{28}$ which suggests that we need to correct the extraction fraction. However, this is an initial report of quantification analysis of $\mathrm{MBF}$ using MDCT examination and comparison of our method with quantitative PET study is necessary to validate its feasibility for the future.

With further development of MDCT (ie, 256-detector row MDCT), dynamic cine scanning of the whole heart will become possible 32 Of course, caution will be needed with the increased radiation dose required. Flow reserve is usually assessed by comparing stress MBF with rest levels. In the present study, only stress blood flow was estimated because the radiation dose during dynamic MDCT is not very low. We need to minimize the radiation dose for clinical use and in that regard MRI is superior to MDCT for evaluation of myocardial perfusion. In our phantom study using a thermo-luminescence dosimeter, the radiation dose for dynamic acquisition was $6.8 \mathrm{mSv}$, compared with approximately $15 \mathrm{mSv}$ for coronary CT-angiography. We may be able to manipulate the dynamic data and interpolate them to reduce the radiation dose by almost $50 \%$. Dose modulation cine scanning using prospective ECG-gating will also reduce the radiation dose in cine acquisition. A radiation dose of approximately half that used for coronary CT-angiography would be better for patients with life threatening CAD.

\section{Study Limitations}

First, the number of patients is small. Second, because the hospital does not have a PET system, we could not compare our method with a quantitative PET study, which is necessary to validate feasibility. Moreover, our 16-MDCT system only has a $20-\mathrm{mm}$ width, so we could not obtain data for the whole myocardium; therefore, a small branch with only a small segment may not have been detected. Future MDCT with wide coverage will solve this problem. Flow reserve is usually assessed by comparing stress MBF with rest values, but we only estimated stress blood flow because the radiation dose for dynamic MDCT is currently too high.

\section{Conclusion}

This study suggests that MDCT can be used to quantifying MBF from first-pass dynamic data.

\section{References}

1. Achenbach S, Ulzheimer S, Baum U, Kachelriess M, Ropers D, Giesler $\mathrm{T}$, et al. Noninvasive coronary angiography by retrospectively ECG-gated multislice spiral CT. Circulation 2000; 102: 2823-2828.

2. Achenbach S, Giesler T, Ropers D, Ulzheimer S, Derlien H, Schulte $\mathrm{C}$, et al. Detection of coronary artery stenoses by contrast-enhanced, retrospectively electrocardiographically-gated, multislice spiral computed tomography. Circulation 2001; 103: 2535-2538.

3. Nieman K, Oudkerk M, Rensing BJ, van Ooijen P, Munne A, van Geuns RJ, et al. Coronary angiography with multi-slice computed tomography. Lancet 2001; 357: 599-603.

4. Achenbach S, Moshage W, Ropers D, Nossen J, Daniel WG. Value of electron-beam computed tomography for the noninvasive detection of high-grade coronary-artery stenoses and occlusions. N Engl J Med 1998; 339: 1964-1971.

5. Funabashi N, Matsumoto A, Yoshida T, Watanabe S, Misumi K, Masuda Y. Usefulness of three-dimensional visualization of coronary arteries using electron-beam computed tomography data with volume rendering. Jpn Circ J 2000; 64: 644-646.

6. Addis KA, Hopper KD, Iyriboz TA, Liu Y, Wise SW, Kasales CJ, et 
al. CT angiography: In vitro comparison of five reconstruction methods. Am J Roentgenol 2001; 177: 1171-1176.

7. Nieman K, Cademartiri F, Lemos PA, Raaijmakers R, Pattynama PM, de Feyter PJ. Reliable noninvasive coronary angiography with fast submillimeter multislice spiral computed tomography. Circulation 2002; 106: $2051-2054$.

8. Sato Y, Matsumoto N, Kato M, Inoue F, Horie T, Kusama J, et al. Noninvasive assessment of coronary artery disease by multislice spiral computed tomography using a new retrospectively ECG-gated image reconstruction technique. Circ J 2003; 67: 401 - 405.

9. Martuscelli E, Romagnoli A, D’Eliseo A, Razzini C, Tomassini M, Sperandio M, et al. Accuracy of thin-slice computed tomography in the detection of coronary stenoses. Eur Heart J 2004; 25: $1043-$ 1048 .

10. Mollet NR, Cademartiri F, Nieman K, Saia F, Lemos PA, McFadden $\mathrm{EP}$, et al. Multislice spiral computed tomography coronary angiography in patients with stable angina pectoris. J Am Coll Cardiol 2004; 43: $2265-2270$.

11. Jinzaki M, Sato K, Tanami Y, Yamada M, Kuribayashi S, Anzai T, et al. Novel method of displaying coronary CT angiography: Angiographic view. Circ J 2006; 70: 1661-1662.

12. Mochizuki T, Murase K, Higashino H, Koyama Y, Doi M, Miyagawa $\mathrm{M}$, et al. Two- and three-dimensional CT ventriculography: A new application of helical CT. Am J Roentgenol 2000; 174: 203-208.

13. Hosoi S, Mochizuki T, Miyagawa M, Shen Y, Murase K, Ikezoe J. Assessment of left ventricular volumes using multi-detector row computed tomography (MDCT): Phantom and human studies. Radiat Med 2003; 21: 62-67.

14. Haraikawa T, Higashino H, Sugawara Y, Miki H, Kurata A, Higaki J, et al. Assessment of left ventricular wall motion using 16-channel multislice computed tomography: Comparison with left ventriculography. Radiat Med 2006; 24: 159-164.

15. Koyama Y, Matsuoka H, Mochizuki T, Higashino H, Kawakami H, Nakata S, et al. Assessment of reperfused acute myocardial infarction with two-phase contrast-enhanced helical CT: Prediction of left ventricular function and wall thickness. Radiology 2005; 235: 804-811.

16. Kurata A, Mochizuki T, Koyama Y, Haraikawa T, Suzuki J, Shigematsu Y, et al. Myocardial perfusion imaging using adenosine triphosphate stress multi-slice spiral computed tomography: Alternative to stress myocardial perfusion scintigraphy. Circ J 2005; 69: $550-557$.

17. Naito H, Saito H, Takamiya M, Hamada S, Yamada N, Imakita S, et al. Quantitative assessment of myocardial enhancement with iodinated contrast medium in patients with ischemic heart disease by using ultrafast X-ray computed tomography. Invest Radiol 1992; 27: 436442 .

18. Naito H, Hamada S, Takamiya M, Yoshibayashi M, Kamiya T, Tamura S. Significance of dipyridamole loading in ultrafast X-ray computed tomography for detection of myocardial ischemia: A study in patients with Kawasaki disease. Invest Radiol 1995; 30: 389-395.

19. Sugiyama H, Naito H, Tsukano S, Yoshibayashi M, Echigo S, Kamiya T. Evaluation by contrast-enhanced electron beam computed tomography of myocardial perfusion and tissue characteristics in congenital aortic stenosis. Circ J 2003; 67: 998-1002.

20. Patlak CS, Blasberg RG. Graphical evaluation of blood-to-brain transfer constants from multiple-time uptake data: Generalizations.
J Cereb Blood Flow Metab 1985; 5: 584-590.

21. Klocke FJ, Baird MG, Lorell BH, Bateman TM, Messer JV, Berman DS, et al. ACC/AHA/ASNC guidelines for the clinical use of cardiac radionuclide imaging: Executive summary: A report of the American College of Cardiology/American Heart Association Task Force on Practice Guidelines (ACC/AHA/ASNC Committee to Revise the 1995 Guidelines for the Clinical Use of Cardiac Radionuclide Imaging). Circulation 2003; 108: 1404-1418.

22. Miyagawa M, Kumano S, Sekiya M, Watanabe K, Akutzu H, Imachi T, et al. Thallium-201 myocardial tomography with intravenous infusion of adenosine triphosphate in diagnosis of coronary artery disease. J Am Coll Cardiol 1995; 26: 1196-1201.

23. Berman DS, Hachamovitch R, Kiat H, Cohen I, Cabico JA, Wang FP, et al. Incremental value of prognostic testing in patients with known or suspected ischemic heart disease: A basis for optimal utilization of exercise technetium-99m sestamibi myocardial perfusion singlephoton emission computed tomography. J Am Coll Cardiol 1995; 26: 639-647.

24. Hachamovitch R, Berman DS, Kiat H, Cohen I, Cabico JA, Friedman $\mathrm{J}$, et al. Exercise myocardial perfusion SPECT in patients without known coronary artery disease: Incremental prognostic value and use in risk stratification. Circulation 1996; 93: 905-914.

25. Hachamovitch R, Berman DS, Shaw LJ, Kiat H, Cohen I, Cabico JA, et al. Incremental prognostic value of myocardial perfusion single photon emission computed tomography for the prediction of cardiac death: Differential stratification for risk of cardiac death and myocardial infarction. Circulation 1998; 97: 535-543.

26. Matsumoto N, Sato Y, Suzuki Y, Kunimasa T, Yoda S, Iida J, et al. Prognostic value of myocardial perfusion single-photon emission computed tomography for the prediction of future cardiac events in a Japanese population: A middle-term follow-up study. Circ J 2007; 71: $1580-1585$.

27. Sakuma H, Suzawa N, Ichikawa Y, Makino K, Hirano T, Kitagawa $\mathrm{K}$, et al. Diagnostic accuracy of stress first-pass contrast-enhanced myocardial perfusion MRI compared with stress myocardial perfusion scintigraphy. Am J Roentgenol 2005; 185: 95-102.

28. Parkka JP, Niemi P, Saraste A, Koskenvuo JW, Komu M, Oikonen $\mathrm{V}$, et al. Comparison of MRI and positron emission tomography for measuring myocardial perfusion reserve in healthy humans. Magn Reson Med 2006; 55: 772-779.

29. Parkash R, deKemp RA, Ruddy TD, Kitsikis A, Hart R, Beauchesne $\mathrm{L}$, et al. Potential utility of rubidium 82 PET quantification in patients with 3-vessel coronary artery disease. J Nucl Cardiol 2004; 11: 440-449.

30. Yoshinaga K, Katoh C, Noriyasu K, Iwado Y, Furuyama H, Ito Y, et al. Reduction of coronary flow reserve in areas with and without ischemia on stress perfusion imaging in patients with coronary artery disease: A study using oxygen 15-labeled water PET. J Nucl Cardiol 2003; 10: $275-283$.

31. Uren NG, Crake T, Lefroy DC, de Silva R, Davies GJ, Maseri A. Reduced coronary vasodilator function in infarcted and normal myocardium after myocardial infarction. N Engl J Med 1994; 331: 222 227.

32. Kido T, Kurata A, Higashino H, Sugawara Y, Okayama H, Higaki J, et al. Cardiac imaging using 256-detector row four-dimensional CT: Preliminary clinical report. Radiat Med 2007; 25: 38-44. 